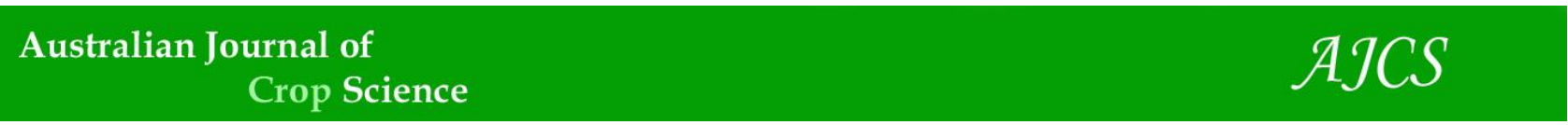

AJCS 15(06):863-870 (2021)

ISSN:1835-2707

doi: 10.21475/ajcs.21.15.06.p2987

\title{
Genetic variability and association of yield and yield components among bread wheat genotypes under drought-stressed conditions
}

\author{
Yared Semahegn ${ }^{1,2^{*}}$, Hussein Shimelis ${ }^{1}$, Mark Laing ${ }^{1}$, Isack Mathew ${ }^{1}$ \\ ${ }^{1}$ School of Agricultural, Earth and Environmental Sciences, African Centre for Crop Improvement, \\ University of KwaZulu-Natal, P. Bag X01, Scottsville 3209, Pietermaritzburg, South Africa \\ ${ }^{2}$ Ethiopian Institute of Agricultural Research, Holetta Research Centre, P.O. Box 2003, Addis Ababa, \\ Ethiopia
}

\section{*Corresponding author: yaredsemahegnb@gmail.com}

\begin{abstract}
Drought is one of the major constraints to wheat production and productivity globally. Developing drought-adapted wheat cultivars is paramount to increase wheat productivity under variable rainfall conditions. Understanding the genetic variability and trait association is key to the development of improved wheat cultivars. The objective of this study was to determine the extent of the genetic parameters and associations of yield and yield components of bread wheat genotypes, in order to design appropriate breeding strategies for yield improvement in wheat. One hundred and twenty genotypes were evaluated at five test sites in the 2018/19 cropping season using a $10 \times 12$ alpha lattice design with two replications. Different sowing dates were used to impose contrasting drought stress levels based on the onset of the main seasonal rains at each site. Data were recorded on agronomic traits such as days to heading (DH), days to maturity (DM), plant height (PH), spike length (SL), spikelet per spike (SS), kernel per spike (KS), 1000 kernel weight (TKW) and grain yield (GY). There was significant $(p<0.01)$ genetic variation for all agronomic traits studied under both drought-stressed and non-stressed conditions. The highest estimates for genetic variance were obtained for $\mathrm{DH}(54.0 \%)$, followed by SL (38.3\%). The high heritability estimated for DH (94.4\%), SL (90.2\%) and SS (85.2\%), coupled with a high rate of genetic advance, suggest that direct selection for these traits would be effective under drought-stressed conditions. GY exhibited low genetic advance (9\%) and heritability (41.5\%) estimates, which were concomitant with its polygenic and complex inheritance pattern. Correlation and path analyses revealed that TKW was the most important contributing trait for improving grain yield under droughtstressed conditions.
\end{abstract}

Keywords: path analysis, heritability, genetic advance, drought, correlation.

\section{Introduction}

Wheat (Triticum aestivum L., $2 \mathrm{n}=6 \mathrm{x}=42$, AABBDD) is an important source of food for more than $30 \%$ of the global human population (Lobell and Gourdji, 2012; Pfeifer et al., 2014). Its importance as a staple food in the sub-Sahara African region has increased rapidly due to socio-economic changes including urbanization, rapid population growth, changes in income per capita and changing lifestyles (Abate et al., 2018). Wheat is one of the most abundant and widely cultivated crops in the world, with about 214 million hectares cultivated annually (FAO, 2019). In the 2018 cropping season in Ethiopia, the wheat production area exceeded 1.7 million hectares, and this produced more than 4.2 million tons of grain (FAO, 2019), making the country one of the major wheat producers in sub-Saharan Africa. However, domestic production falls short of national demand for self-sufficiency. As a result, wheat has to be imported (Rashid and Lemma, 2014; Abate et al., 2018).

The productivity of wheat in Ethiopia is about 2.4 tons ha-1 compared to 3.4 tons ha $^{-1}$ world average (FAO, 2019). The relatively low productivity of wheat in Ethiopia has been attributed to biotic and abiotic stresses. Drought stress, which is exacerbated by climate variability, is the major abiotic stress curtailing wheat productivity in sub-Sahara Africa including Ethiopia (Tadesse et al., 2019). Breeding wheat varieties that are resilient to adverse environmental conditions and then cultivating them with improved production technologies will ensure high productivity and more sustainable production of wheat in Ethiopia (Negassa et al., 2013).

Developing drought tolerant cultivars that can withstand terminal drought, which is prevalent in low-lying areas of Ethiopia, is key to improving wheat productivity. The success of any attempts to improve drought tolerance in wheat will depend on the amount of genetic variation available. Semahegn et al. (2020) reported the presence of significant genetic variation for yield and related traits in bread wheat genotypes evaluated under drought-stressed and nonstressed conditions, which would provide important genetic resources for a drought tolerance-breeding program. However, there is a need to investigate the genetic basis and association among yield and yield components to design suitable breeding strategies for yield and drought tolerance improvement. 
Heritability estimates help to predict performance of progenies and to forecast potential genetic gains from selection (Ali et al., 2010). Traits with high heritability estimates accompanied with high genetic advance can be selected more effectively via direct selection (Ali et al., 2009b; Ali et al., 2010; Farshadfar et al., 2014; Okechukwu et al., 2015; Abraha et al., 2017). Yield components have been reported to have higher heritability estimates than grain yield per se, which facilitates indirect selection for grain yield under variable environments (Mathew et al., 2018). Hence, selection of agronomic traits with favourable correlations with grain yield is used to indirectly improve grain yield and drought tolerance in most crops, including wheat (Dodig et al., 2012; Asfaw and Blair, 2014; Lopes et al., 2015; Abraha et al., 2017; Mathew et al., 2018). Mwadzingeni et al. (2017) and Mathew et al. (2018) evaluated variance components in wheat and found that grain yield had the least genetic variance, heritability and genetic gain estimates, and recommended indirect selection using highly heritable and yield-influencing agronomic traits. However, other reports cite different estimates for the variance components, showing that variance components evaluated in different populations may only serve as a guide, and that evaluating each population individually is needed for practical breeding purposes.

The amount of genetic gain observed in grain yield after indirect selection via yield components is influenced by the association between the trait and grain yield. Thus, evaluating correlations among grain yield and its components would be helpful in selecting the target traits for simultaneous selection for high yield and drought tolerance (Ali et al., 2009a; Kandic et al., 2009; Ali et al., 2011; Baranwal et al., 2012; Seher et al., 2015). Simple correlations may be inadequate in quantifying the importance of each yield component where there are several components directly and indirectly contributing to the final yield (Bizeti et al., 2004; Sreckov et al., 2011). Therefore, there is a need for a more in-depth analysis such as the path coefficient analysis, which partitions the observed correlation into direct and indirect contributory effects (Garcia del Moral et al., 2003; Ali et al., 2009a; Kandic et al., 2009; Baranwal et al., 2012). The variations in path coefficients of yield components in relation to grain yield have been reported by several studies (Subhani and Chowdhry, 2000; Khaliq et al., 2004; Anwar et al., 2009; Khan et al., 2010; Baranwal et al., 2012). These show that correlations and path coefficients are specific to a population under investigation and the prevailing environmental conditions. Therefore, there is a need to deduce the associations among yield and yield components for each population and environment to serve as a guide during the designing of a breeding program. Given the above background, the present investigation was undertaken to estimate genetic parameters and association of yield and yield components of bread wheat genotypes evaluated under drought-stressed and non-stressed conditions to guide for drought tolerance breeding for enhanced yield gains in moisture stress areas of Ethiopia.

\section{Results}

\section{Analysis of variance}

Separate and combined analyses of variance showed that the test genotypes were significantly $(p<0.01)$ different for all the traits measured under drought-stressed and non-stressed conditions (Table 1). Under the non-stressed conditions, genotype by site interaction was significant for all traits except KS. In contrast, the genotype by site interaction effects were significant for $\mathrm{DH}, \mathrm{DM}, \mathrm{PH}, \mathrm{TKW}$ and $\mathrm{GY}$ under the drought-stressed conditions. Across all sites and water regimes, the three-way (genotype $x$ water regime $x$ site) interaction effect had a significant impact on $\mathrm{DH}, \mathrm{DM}, \mathrm{SL}$ and TKW. The genotypes also exhibited differential response under different moisture regimes, as indicated by the significant genotype by water regime interaction effects for DH, DM and SL.

\section{Variance components, heritability and genetic advance}

The results from the separate and combined variance component analyses indicated that phenotypic variances were higher than genotypic variances in all the measured traits (Table 2). Under the non-stressed conditions, the highest genotypic variance was recorded for DH (68.1\%), followed by SL (55.3\%) and SS (31.3\%). Similarly, DH recorded the highest genetic variance of $62.3 \%$ under drought- stressed conditions followed by DM (35.9\%) and SL (27.7\%). Genetic variance decreased under drought-stressed conditions compared to non-stressed conditions for traits such as DH, SL, SS and KS. The genetic variance for grain yield was $4.4 \%$ under non-stressed conditions as compared to $8.9 \%$ under droughtstressed conditions. A combined analysis of variance across all test environments was conducted to test the consistency of genetic and environmental effects on traits performances. Overall, the highest genotypic variance was also recorded for DH (54.0\%) followed by SL (38.6\%), while GY (4.5\%) had the lowest. Broad sense heritability values ranged from 28.1 to $94.2 \%$ under non-stressed conditions while a range of 44.6 to 91.5\% was observed under drought-stressed conditions. Across the test environments, broad sense heritability values ranged between 41.5 and $94.4 \%$. DH, SL and SS had high heritability estimates (above 79\%) under both droughtstressed and non-stressed conditions. GY had the lowest heritability $(<45 \%)$ under both conditions. The maximum genetic advance was recorded for SL (15.1\%) followed by DH (14.6\%), SS (12.7\%) and KS (11.8\%) under non-stressed conditions while GY (14.9\%) showed the maximum genetic advance followed by SL (11.9\%), TKW (10.9\%) and SS (10.7\%) under drought-stressed conditions. Across test environments, the maximum genetic advance was observed in SL (13.4\%) followed by DH (12.2\%), KS (12.2\%) and SS (11.6\%). Concomitant with high genetic variance and heritability estimates, the highest genetic advance (>12\%) was achieved in $\mathrm{DH}$ and SL under both non-stressed and drought-stressed conditions.

\section{Correlation of yield and yield components}

GY exhibited the strongest association with TKW under both drought-stressed and non-stressed conditions (Table 3). Under drought-stressed conditions, the coefficient of correlation between GY and TKW was 0.49 (Table 3, above diagonal) compared to 0.45 under non-stressed conditions (Table 3, below diagonal). GY also exhibited stronger associations with PH $(r=0.49 ; p<0.01)$ and $S L(r=0.24 ; p<0.01)$ under drought-stressed conditions. Likewise, there were significant correlations between GY with PH $(r=0.26 ; p<0.01)$ and KS $(r=0.28 ; p<0.01)$. GY exhibited negative correlations with $\mathrm{DH}(r=-0.27 ; p<0.01)$ and DM $(r=-0.19 ; p<0.05)$ under non-stressed conditions while these traits showed nonsignificant association with GY under drought-stressed conditions. $\mathrm{DH}$ and $\mathrm{DM}$ showed strong positive correlations with each other $(r \geq 0.80 ; p<0.01)$ under both drought-stressed and non-stressed conditions. 


\section{Path coefficient analysis}

Under non-stressed conditions, TKW, SS and KS recorded strong and positive direct effects with values of $0.51,0.23$ and 0.20 on GY (Table 4, boldfaced text). In comparison, $\mathrm{PH}(0.37)$, TKW (0.26) and KS (0.23) exhibited strong positive direct effects on GY under drought-stressed conditions. SS (-0.44) showed the highest but negative direct effect on GY under drought-stressed conditions. The highest positive indirect effects on GY were 0.14 and 0.13 , under non-stressed and drought-stressed conditions, respectively, exhibited by $\mathrm{PH}$ through TKW. Similarly, the high but negative indirect effects on GY under non-stressed conditions were exhibited through TKW by DH $(-0.24)$ and DM $(-0.18)$. Under the droughtstressed conditions, DH (-0.27), DM (-0.25), SL $(-0.26)$ and KS $(-0.28)$ had substantial indirect reducing effects on GY through SS.

\section{Discussion}

The analysis of variance showed that genotypic effects were significant for all the traits under the different environmental conditions, which confirmed the presence of genetic variation for wheat improvement. Mwadzingeni et al. (2017) and Mathew et al. (2018) reported the presence of significant genetic variation in yield and yield components of wheat under drought-stressed and non-stressed conditions evaluated in the field and greenhouse. Useful genetic variability among the test bread wheat genotypes for traits related to drought tolerance is of paramount importance for successful breeding aimed to develop wheat cultivars adapted to a range of stress environments. The performance of the different genotypes varied with changes in environmental conditions. The significant impact of the environment on genotypic performance can present both opportunities and challenges during selection (Kang, 2002). Environmental influence can allow selection of genotypes with superior performance for specific or broad adaptation (Annicchiarico, 1997; Kang, 2002; Badu-Aprku et al., 2017; Mafouasson et al., 2018). On the other hand, environmental influence can also confound selection and increase the number of selection cycles to identify superior genotypes. The increase in requisite selection cycles has high cost implications during breeding leading to premature abandonment of some wheat breeding programs. Environmental influence on genotype performance is widely reported in wheat (Marti and Slafer, 2014; Mwadzingeni et al., 2017; Mathew et al., 2018).

The higher estimates for phenotypic variance compared to genotypic variance showed that the environment had greater effects on conditioning phenotypic traits than the genetic constitution of the test genotypes. The high environmental variance was expected since quantitative traits such as grain yield are known to be significantly affected by changes in environmental conditions such as water availability (Mwadzingeni et al., 2017; Mathew et al., 2018). This condition varied between the drought-stressed and nonstressed conditions, and from one site to another. The differential performance of the genotypes necessitates the need to separate the genetic from environmental variance components, and quantify the contribution of each component in order to devise efficient breeding strategies for target environments (Farshadfar et al., 2014). The genetic component is the most important for breeding purposes because it affects the portion of variation that is passed to offspring during the breeding process. The high genetic variance estimates for traits such as $\mathrm{DH}$ and $\mathrm{SL}$, implied that these traits were less influenced by environmental factors and can be effectively and directly selected based on their phenotypic expression (Shimelis and Shiringani, 2010). Similarly, Mathew et al. (2018) found high genetic variance estimates, above $75 \%$, for $\mathrm{DH}$ under drought-stressed and non-stressed conditions and concluded that water availability had less impact on flowering compared to grain yield, which had lower genetic variance. The overall genetic variance for GY of $4.5 \%$ found in this study was also comparable to $3.95 \%$ reported by Mathew et al. (2018). Traits with low genetic variance such as GY will be difficult to improve by direct selection under various environments since their selection would be confounded by large variation across the different test environments.

The heritability estimates ranged from moderate $(41.5 \%, \mathrm{GY})$ to high $(94.4 \%, \mathrm{DH})$, which is concomitant with variation in genetic control of different traits. Variation in heritability estimates imply that the different traits cannot be improved through the same breeding strategy. Similar ranges of heritability estimates (between 30 and 95\%) for agronomic traits in wheat have been reported (Okechukwu et al., 2015; Mwadzingeni et al., 2016; Mathew et al., 2018). Baranwal et al. (2012) also reported high broad sense heritability estimates for DH, PH and KS. Similarly, Kandic et al. (2009) reported high broad sense heritability for $\mathrm{DH}$. The heritability estimates for GY were moderate, which is attributable to the polygenic nature and complexity of GY. The heritability estimates for GY were comparable to 22.1, 38.9 and 39.0\% reported by Ali et al. (2010), Mwadzingeni et al. (2016) and Okechukwu et al. (2015), respectively. However, heritability estimates as high as $74 \%$ have also been reported previously (Kandic et al., 2009; Farshadfar et al., 2014). High heritability estimates along with high genetic advance were calculated for $\mathrm{DH}, \mathrm{SL}$ and SS, suggesting that these traits were under the influence of additive genes, which favours their improvement via direct selection, even under drought stress conditions (Ali et al., 2009b; Farshadfar et al., 2014). Several other studies have reported high heritability and genetic advance for traits such as DH, PH, SL and TKW (Ali et al., 2010; Gashaw et al., 2010; Riaz-ud-din et al., 2010). The high heritability and genetic advance of these traits would increase their importance in the improvement of drought tolerance and GY. Traits with poor genetic advance and low heritability estimates are difficult to select directly and should be indirectly selected via related traits. Indirect selection for positively associated traits with high heritability and genetic advance values will enhance genotypic response to selection under various environmental conditions (Okechukwu et al., 2015; Mwadzingeni et al., 2017). The yield-related traits exhibited various levels of associations with GY in line with their genetic relationship and environmental impact. The associations showed variation between the different environments showing that the level of association between traits is influenced by prevailing conditions such as water availability. Therefore, selection strategies must account for these changes in trait association. TKW and PH exhibited the strongest positive direct associations with GY, which corroborated previous studies (Kandic et al., 2009; Lopes et al., 2015; Okechukwu et al., 2015). Thus, selecting for taller plants with heavier seed weight would potentially improve GY. However, increased PH is often associated with lodging under particular circumstances (Tadesse et al., 2010; Okechukwu et al., 2015). Baranwal et al. (2012) reported 
Table 1. Analysis of variance for eight agronomic traits of 120 wheat genotypes evaluated across five sites under drought-stressed and non-stressed conditions.

\begin{tabular}{|c|c|c|c|c|c|c|c|c|c|}
\hline \multicolumn{10}{|c|}{ Non-stressed conditions } \\
\hline Source & DF & $\mathrm{DH}$ & DM & $\mathrm{PH}$ & SL & SS & KS & TKW & GY \\
\hline Genotype (G) & 119 & $163.69 * *$ & $29.28 * *$ & $112.80 * *$ & $3.75^{* *}$ & $14.96 * *$ & $140.47 * *$ & $42.70 * *$ & $3892054 * *$ \\
\hline Site (S) & 4 & $9582.91 * *$ & $49046.03^{* *}$ & $63899.16^{* *}$ & $197.42 * *$ & $996.19 * *$ & $56793.72^{* *}$ & $5485.97 * *$ & $3839403937 * *$ \\
\hline$G \times S$ & 475 & $10.21 * *$ & $7.25^{* *}$ & $40.14 * *$ & $0.36^{* *}$ & $3.18^{*}$ & $43.54^{\text {ns }}$ & $18.94 * *$ & $2871349 * *$ \\
\hline Residual & 471 & 5.53 & 5.39 & 29.13 & 0.25 & 2.64 & 39.62 & 10.73 & 2042798 \\
\hline $\mathrm{CV}(\%)$ & & 4.12 & 2.38 & 8.32 & 6.19 & 9.59 & 14.33 & 11.37 & 25.71 \\
\hline \multicolumn{10}{|c|}{ Drought-stressed conditions } \\
\hline Source & DF & $\mathrm{DH}$ & DM & $\mathrm{PH}$ & SL & SS & KS & TKW & GY \\
\hline Genotype (G) & 119 & $50.07 * *$ & $52.73 * *$ & $72.09 * *$ & $2.01 * *$ & $6.12^{* *}$ & $73.34 * *$ & $31.36 * *$ & $1566950 * *$ \\
\hline Site (S) & 4 & $2313.14^{* *}$ & $10416.08^{* *}$ & $26536.53^{* *}$ & $126.40 * *$ & $594.05^{* *}$ & $16252.06^{* *}$ & $4358.83 * *$ & $596074218 * *$ \\
\hline $\mathrm{G} \times \mathrm{S}$ & 292 & $7.07^{* *}$ & $16.56^{* *}$ & $30.02 *$ & $0.70^{\text {ns }}$ & $2.21^{\mathrm{ns}}$ & $45.18^{\text {ns }}$ & $16.57^{* *}$ & $1128435^{* *}$ \\
\hline Residual & 206 & 2.68 & 9.25 & 23.65 & 0.73 & 1.81 & 41.42 & 11.79 & 816533 \\
\hline CV (\%) & & 2.71 & 3.09 & 8.91 & 10.45 & 8.54 & 16.24 & 12.49 & 30.9 \\
\hline \multicolumn{10}{|l|}{ Combined } \\
\hline Source & DF & $\mathrm{DH}$ & DM & $\mathrm{PH}$ & $\mathrm{SL}$ & SS & KS & TKW & GY \\
\hline Genotype (G) & 119 & $169.69 * *$ & $74.76 * *$ & $157.80 * *$ & $4.43^{* *}$ & $15.56 * *$ & $153.71 * *$ & $52.39 * *$ & $3563640 * *$ \\
\hline Water regime (WR) & 1 & $941.99 * *$ & $1989.85^{* *}$ & $47047^{* *}$ & $14.43^{* *}$ & $669.31 * *$ & $18413.3 * *$ & $739.90 * *$ & $2017521970 * *$ \\
\hline Site (S) & 4 & $10136.7^{* *}$ & $46284.5 * *$ & $79858.5^{* *}$ & $222.42 * *$ & $837.44^{* *}$ & $54672.6 * *$ & $5300.01 * *$ & $2928323307^{* *}$ \\
\hline$G \times W R$ & 119 & $11.72 * *$ & $13.34^{* *}$ & $35.26^{\text {ns }}$ & $0.60113^{* *}$ & $2.89^{n s}$ & $50.81^{\text {ns }}$ & $14.33^{\text {ns }}$ & $1518069^{n s}$ \\
\hline $\mathrm{G} \times \mathrm{S}$ & 476 & $8.67 * *$ & $12.17^{* *}$ & $41.51^{* *}$ & $0.46^{\text {ns }}$ & $3.03 *$ & $45.22^{\mathrm{ns}}$ & $19.65^{* *}$ & $2417996 * *$ \\
\hline$W R \times S$ & 4 & $736.54^{* *}$ & $3416.88^{* *}$ & $6904.42 * *$ & $90.49 * *$ & $548.27^{* *}$ & $9039.31 * *$ & $2105.12 * *$ & $365811796^{* *}$ \\
\hline$G \times W R \times S$ & 301 & $13.87^{* *}$ & $10.54 * *$ & $32.08^{\text {ns }}$ & $0.52 *$ & $2.74^{\mathrm{ns}}$ & $47.19^{\text {ns }}$ & $16.07^{* *}$ & $1961002^{\text {ns }}$ \\
\hline Residual & 747 & 6.47 & 7.52 & 30.78 & 0.43 & 2.56 & 42.53 & 11.77 & 1725414 \\
\hline CV (\%) & & 4.4 & 2.8 & 9.1 & 8.1 & 9.7 & 15.4 & 12.1 & 28.8 \\
\hline
\end{tabular}

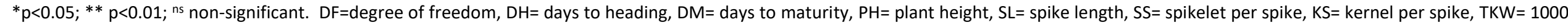
kernel weight, $\mathrm{GY}=$ grain yield, $\mathrm{CV}=$ coefficient of variation. 


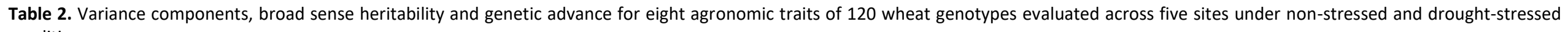
conditions.

\begin{tabular}{|c|c|c|c|c|c|c|c|c|c|c|c|c|c|c|c|c|}
\hline \multirow[t]{3}{*}{ Component } & \multicolumn{16}{|c|}{ Non-stressed conditions } \\
\hline & \multicolumn{2}{|l|}{$\mathrm{DH}$} & \multicolumn{2}{|l|}{ DM } & \multicolumn{2}{|l|}{ PH } & \multicolumn{2}{|l|}{ SL } & \multicolumn{2}{|l|}{ SS } & \multicolumn{2}{|l|}{ KS } & \multicolumn{2}{|l|}{ TKW } & \multicolumn{2}{|l|}{ GY } \\
\hline & var & $\%$ & var & $\%$ & var & $\%$ & var & $\%$ & var & $\%$ & var & $\%$ & var & $\%$ & var & $\%$ \\
\hline Genotype (G) & 17.52 & 68.1 & 2.51 & 28.0 & 8.29 & 19.0 & 0.39 & 55.3 & 1.34 & 31.3 & 9.92 & 17.3 & 2.71 & 15.0 & 116497.6 & 4.4 \\
\hline $\mathrm{G} \times$ Site & 2.67 & 10.4 & 1.06 & 11.8 & 6.27 & 14.4 & 0.06 & 9.0 & 0.31 & 7.2 & 7.93 & 13.8 & 4.68 & 25.8 & 472001.3 & 17.9 \\
\hline Residual & 5.53 & 21.5 & 5.39 & 60.2 & 29.13 & 66.7 & 0.25 & 35.7 & 2.64 & 61.5 & 39.62 & 68.9 & 10.73 & 59.2 & 2042798 & 77.6 \\
\hline Total variance & 25.71 & & 8.96 & & 43.70 & & 0.70 & & 4.29 & & 57.47 & & 18.12 & & 2631297 & \\
\hline$\delta^{2} p$ & 18.60 & & 3.27 & & 12.46 & & 0.42 & & 1.67 & & 15.45 & & 4.72 & & 415177.6 & \\
\hline Heritability (\%) & 94.2 & & 77.0 & & 66.6 & & 91.2 & & 80.5 & & 64.1 & & 57.5 & & 28.1 & \\
\hline \multirow[t]{2}{*}{ GAM (\%) } & 14.6 & & 2.9 & & 7.4 & & 15.1 & & 12.7 & & 11.8 & & 8.9 & & 6.7 & \\
\hline & \multicolumn{16}{|c|}{ Drought-stressed conditions } \\
\hline Genotype (G) & 9.44 & 62.3 & 8.00 & 35.9 & 9.28 & 24.8 & 0.28 & 27.7 & 0.86 & 29.2 & 6.20 & 12.3 & 3.30 & 17.9 & 100556.3 & 8.9 \\
\hline G $\times$ Site & 3.04 & 20.0 & 5.06 & 22.7 & 4.41 & 11.8 & 0 & 0 & 0.28 & 9.4 & 2.60 & 5.2 & 3.31 & 18.0 & 216013.6 & 19.1 \\
\hline Residual & 2.68 & 17.7 & 9.25 & 41.4 & 23.65 & 63.3 & 0.73 & 72.3 & 1.81 & 61.6 & 41.42 & 82.5 & 11.79 & 64.1 & 816533 & 72.1 \\
\hline Total variance & 15.17 & & 22.32 & & 37.34 & & 1.01 & & 2.94 & & 50.22 & & 18.40 & & 1133103 & \\
\hline$\delta^{2} p$ & 10.32 & & 9.94 & & 12.52 & & 0.35 & & 1.1 & & 10.86 & & 5.14 & & 225412.4 & \\
\hline Heritability (\%) & 91.5 & & 80.5 & & 74.1 & & 79.2 & & 78.4 & & 57.1 & & 64.2 & & 44.6 & \\
\hline \multirow[t]{2}{*}{ GAM (\%) } & 10.0 & & 5.3 & & 9.9 & & 11.9 & & 10.7 & & 9.8 & & 10.9 & & 14.9 & \\
\hline & \multicolumn{16}{|c|}{ Combined } \\
\hline Genotype (G) & 12.69 & 54.0 & 4.85 & 31.8 & 9.19 & 20.5 & 0.31 & 38.6 & 1.00 & 26.4 & 8.36 & 15.4 & 2.69 & 14.6 & 95805.8 & 4.5 \\
\hline $\begin{array}{l}\text { Gx Water regime } \\
(\mathrm{WR})\end{array}$ & 0 & 0 & 0.48 & 3.2 & 0.55 & 1.2 & 0.01 & 1.8 & 0.03 & 0.7 & 0.63 & 1.2 & 0 & 0 & 0 & 0 \\
\hline G $\times$ Site & 0 & 0 & 0.65 & 4.2 & 3.59 & 8.0 & 0 & 0 & 0.11 & 2.9 & 0 & 0 & 1.41 & 7.7 & 175797.7 & 8.2 \\
\hline $\mathrm{G} \times \mathrm{WR} \times$ Site & 4.34 & 18.5 & 1.77 & 11.6 & 0.76 & 1.7 & 0.05 & 6.2 & 0.10 & 2.7 & 2.74 & 5.0 & 2.52 & 13.7 & 138345.2 & 6.5 \\
\hline Residual & 6.47 & 27.5 & 7.52 & 49.2 & 30.78 & 68.6 & 0.43 & 53.1 & 2.56 & 67.2 & 42.53 & 78.4 & 11.77 & 64.0 & 1725414 & 80.8 \\
\hline Total variance & 23.51 & & 15.28 & & 44.87 & & 0.81 & & 3.81 & & 54.25 & & 18.39 & & 2135363 & \\
\hline$\delta^{2} p$ & 13.45 & & 5.78 & & 11.80 & & 0.34 & & 1.18 & & 11.07 & & 3.81 & & 231070.5 & \\
\hline Heritability (\%) & 94.4 & & 84.0 & & 77.9 & & 90.2 & & 85.2 & & 75.5 & & 70.6 & & 41.5 & \\
\hline GAM (\%) & 12.2 & & 4.3 & & 9.0 & & 13.4 & & 11.6 & & 12.2 & & 10.0 & & 9.0 & \\
\hline
\end{tabular}

$\mathrm{DH}=$ days to heading, $\mathrm{DM}=$ days to maturity, $\mathrm{PH}=$ plant height, $\mathrm{SL}=$ spike length, $\mathrm{SS}=$ spikelet per spike, $\mathrm{KS}=$ kernel per spike, $\mathrm{TKW}=1000$ kernel weight, $\mathrm{GY}=$ grain yield, var= variance, $\mathrm{GAM}=$ genetic advance as percent of mean, $\delta^{2} \mathrm{p}=$ phenotypic variance. 
Table 3. Pearson correlation coefficients for eight agronomic traits of 120 wheat genotypes evaluated under drought-stressed and non- stressed conditions in five test sites.

\begin{tabular}{|c|c|c|c|c|c|c|c|c|}
\hline \multirow[t]{2}{*}{ Traits } & \multicolumn{8}{|c|}{ Drought-stressed conditions } \\
\hline & $\mathrm{DH}$ & DM & $\mathrm{PH}$ & SL & SS & KS & TKW & GY \\
\hline $\mathrm{DH}$ & 1 & $0.86 * *$ & $0.06^{\mathrm{ns}}$ & $0.27 * *$ & $0.61 * *$ & $0.48^{* *}$ & $0.09^{\text {ns }}$ & $-0.01^{\mathrm{ns}}$ \\
\hline DM & $0.80 * *$ & 1 & $0.26 * *$ & $0.37 * *$ & $0.56 * *$ & $0.50 * *$ & $0.17^{\text {ns }}$ & $0.15^{\mathrm{ns}}$ \\
\hline $\mathrm{PH}$ & $-0.15^{\mathrm{ns}}$ & $0.00^{\text {ns }}$ & 1 & $0.45^{* *}$ & $0.27 * *$ & $0.14^{\mathrm{ns}}$ & $0.48 * *$ & $0.49 * *$ \\
\hline SL & $0.24 * *$ & $0.31 * *$ & $0.37 * *$ & 1 & $0.58 * *$ & $0.33^{* *}$ & $0.35 * *$ & $0.24 * *$ \\
\hline SS & $0.54 * *$ & $0.53 * *$ & $0.12^{\text {ns }}$ & $0.53 * *$ & 1 & $0.63 * *$ & $0.10^{\text {ns }}$ & $-0.04^{\text {ns }}$ \\
\hline KS & $0.01^{\mathrm{ns}}$ & $0.07^{n s}$ & $0.08^{\text {ns }}$ & $0.21^{*}$ & $0.57 * *$ & 1 & $-0.02^{\mathrm{ns}}$ & $0.09^{n s}$ \\
\hline TKW & $-0.48 * *$ & $-0.35 * *$ & $0.28 * *$ & $0.11^{\text {ns }}$ & $-0.31 * *$ & $-0.08^{\mathrm{ns}}$ & 1 & $0.49 * *$ \\
\hline GY & $-0.27^{* *}$ & $-0.19 *$ & $0.26 * *$ & $0.13^{\text {ns }}$ & $0.08^{\mathrm{ns}}$ & $0.28 * *$ & $0.45^{* *}$ & 1 \\
\hline
\end{tabular}

${ }^{*} \mathrm{p}<0.05 ;{ }^{* *} \mathrm{p}<0.01$; ${ }^{\mathrm{n}}$ non-significant. $\mathrm{DH}=$ days to heading, $\mathrm{DM}=$ days to maturity, $\mathrm{PH}=$ plant height, $\mathrm{SL}=$ spike length, $\mathrm{SS}=\mathrm{spikelet}$ per $\mathrm{spike}, \mathrm{KS}=\mathrm{kernel}$ per spike, $\mathrm{TKW}=$ 1000 kernel weight, $\mathrm{GY}=$ grain yield.

Table 4. The direct (bold-faced values) and indirect effects of seven agronomic traits on grain yield of 120 wheat genotypes evaluated in drought-stressed and non-stressed conditions across the five test sites.

\begin{tabular}{|c|c|c|c|c|c|c|c|c|c|}
\hline & & $\mathrm{DH}$ & DM & $\mathrm{PH}$ & $S L$ & SS & KS & TKW & rGY \\
\hline \multirow[t]{2}{*}{$\mathrm{DH}$} & NS & -0.04 & -0.08 & -0.02 & -0.02 & 0.13 & 0.00 & -0.24 & $-0.27^{* *}$ \\
\hline & DS & 0.00 & 0.07 & 0.02 & 0.03 & -0.27 & 0.11 & 0.02 & $-0.01^{\mathrm{ns}}$ \\
\hline \multirow[t]{2}{*}{ DM } & NS & -0.03 & -0.10 & 0.00 & -0.03 & 0.12 & 0.02 & -0.18 & $-0.19 *$ \\
\hline & DS & 0.00 & 0.08 & 0.10 & 0.05 & -0.25 & 0.12 & 0.04 & $0.15^{\mathrm{ns}}$ \\
\hline \multirow[t]{2}{*}{$\mathrm{PH}$} & NS & 0.01 & 0.00 & 0.11 & -0.03 & 0.03 & 0.02 & 0.14 & $0.26^{* *}$ \\
\hline & DS & 0.00 & 0.02 & 0.37 & 0.06 & -0.12 & 0.03 & 0.13 & $0.49 * *$ \\
\hline \multirow[t]{2}{*}{ SL } & NS & -0.01 & -0.03 & 0.04 & -0.09 & 0.12 & 0.04 & 0.05 & $0.13^{\text {ns }}$ \\
\hline & DS & 0.00 & 0.03 & 0.17 & 0.13 & -0.26 & 0.08 & 0.09 & $0.24^{* *}$ \\
\hline \multirow[t]{2}{*}{ SS } & NS & -0.02 & -0.05 & 0.01 & -0.05 & 0.23 & 0.12 & -0.16 & $0.08^{\text {ns }}$ \\
\hline & DS & 0.00 & 0.05 & 0.10 & 0.07 & -0.44 & 0.15 & 0.03 & $-0.04^{\mathrm{ns}}$ \\
\hline \multirow[t]{2}{*}{ KS } & NS & 0.00 & -0.01 & 0.01 & -0.02 & 0.13 & 0.20 & -0.04 & $0.28 * *$ \\
\hline & DS & 0.00 & 0.04 & 0.05 & 0.04 & -0.28 & 0.23 & 0.00 & $0.09^{n s}$ \\
\hline \multirow[t]{2}{*}{ TKW } & NS & 0.02 & 0.03 & 0.03 & -0.01 & -0.07 & -0.02 & 0.51 & $0.49 * *$ \\
\hline & DS & 0.00 & 0.01 & 0.18 & 0.04 & -0.04 & 0.00 & 0.26 & $0.45^{* *}$ \\
\hline
\end{tabular}

$* \mathrm{p}<0.05 ; * \mathrm{p}<0.01 ;{ }^{\mathrm{ns}}$ non-significant. NS= non-stressed conditions, $\mathrm{DS}=$ drought-stressed conditions, $\mathrm{DH}=$ days to heading, $\mathrm{DM}=$ days to $\mathrm{maturity}, \mathrm{PH}=\mathrm{plant}$ height, $\mathrm{SL}=$ spike length, $\mathrm{SS}=$ spikelet per spike, $\mathrm{KS}=$ kernel per spike, $\mathrm{GY}=$ grain yield, $\mathrm{TKW}=1000$ kernel weight, $\mathrm{rGY}=$ correlation with grain yield.

Table 5. Geographic and climatic descriptors of the study sites.

\begin{tabular}{|c|c|c|c|c|c|c|c|c|}
\hline \multirow[t]{2}{*}{ Sites } & \multicolumn{3}{|c|}{ Geographic position } & \multirow{2}{*}{$\begin{array}{l}\text { Rainfall } \\
(\mathrm{mm})\end{array}$} & \multicolumn{2}{|c|}{ Temperature $\left({ }^{\circ} \mathrm{C}\right)$} & \multicolumn{2}{|l|}{ Soil } \\
\hline & Latitude & Longitude & $\begin{array}{l}\text { Altitude } \\
\text { (masl) }\end{array}$ & & Minimum & Maximum & Texture & $\mathrm{pH}$ \\
\hline Alem Tena & $8.3^{\circ} 18^{\prime} \mathrm{N}$ & $38.4^{\circ} 57^{\prime} \mathrm{E}$ & 1611 & 1054.5 & 10.4 & 26.1 & Clay loam & 7.0 \\
\hline Debre Zeit & $8.7^{\circ} 44^{\prime} \mathrm{N}$ & $39.0^{\circ} 58^{\prime} \mathrm{E}$ & 1920 & 931.4 & 11.4 & 27.5 & Clay & 7.5 \\
\hline Dera & $8.3^{\circ} 20^{\prime} \mathrm{N}$ & $39.3^{\circ} 19^{\prime} \mathrm{E}$ & 1500 & 816.1 & 13.7 & 29.4 & Clay & 7.8 \\
\hline Kulumsa & $8.0^{\circ} 02^{\prime} \mathrm{N}$ & $39.2^{\circ} 10^{\prime} \mathrm{E}$ & 2200 & 946 & 9.9 & 23.1 & Clay & 6.8 \\
\hline Melkasa & $8.4^{\circ} 24^{\prime} \mathrm{N}$ & $39.3^{\circ} 21^{\prime} \mathrm{E}$ & 1500 & 807.3 & 14.1 & 29.9 & Clay loam & 7.2 \\
\hline
\end{tabular}

masl= metres above sea level.

Table 6. Partial computation of expected mean squares for the wheat genotypes evaluated on five sites and two water regimes.

\begin{tabular}{|c|c|c|}
\hline Source of variation & Degree of freedom & Expected mean square \\
\hline Genotypes (g) & $\mathrm{g}-1$ & $\sigma_{\mathrm{e}}^{2}+r \sigma_{\mathrm{gsw}}^{2}+r w \sigma_{\mathrm{gs}}^{2}+r s \sigma_{\mathrm{gw}}^{2}+\sigma_{\mathrm{g}}^{2}$ \\
\hline Sites $(s)$ & $s-1$ & - \\
\hline Water regime $(w)$ & $w-1$ & - \\
\hline gs & $(g-1)(s-1)$ & $\sigma_{e}^{2}+r \sigma_{g s w}^{2}+r s \sigma_{g w}^{2}+r w \sigma_{g s}^{2}$ \\
\hline gw & $(g-1)(w-1)$ & $\sigma_{e}^{2}+r \sigma_{g s w}^{2}+r s \sigma_{g w}^{2}$ \\
\hline gsw & $(g-1)(s-1)(w-1)$ & $\sigma_{e}^{2}+r \sigma_{g s w}^{2}$ \\
\hline Residual & $\operatorname{sw}(g-1)(r-1)$ & $\sigma^{2} \mathrm{e}$ \\
\hline
\end{tabular}


significant and negative correlation between $\mathrm{GY}$ and $\mathrm{PH}$, which would allow for simultaneous GY improvement and reduction in susceptibility to lodging. Early flowering and maturity were associated with higher GY under non-stressed conditions, which might be attributed to shorter vegetative period (Shavrukov et al., 2017) and an extended grain-filling period (Dodig et al., 2012).

\section{Materials and Methods}

\section{Plant materials and trial conditions}

One hundred and twenty bread wheat genotypes comprising of 115 breeding lines that were being developed for drought stress areas that had International Maize and Wheat Improvement Centre (CIMMYT) origin and five standard checks that were released as drought tolerant cultivars were tested in five sites in the 2018/19 cropping season using a $10 \times 12$ alpha lattice design with two replications. Details of the genotypes along with their pedigree is presented in Appendix 1. The test sites were Alem Tena, Debre Zeit, Dera, Kulumsa and Melkasa. The geographic, climatic and soil properties of the test sites are presented in Table 5. Two contrasting moisture regimes were imposed using two different sowing dates (early planting representing nonstressed, while late planting as drought stressed conditions) as described in Semahegn et al. (2020).

Data collection and analysis

Data were recorded on days to heading $(\mathrm{DH})$, days to maturity (DM), plant height $(\mathrm{PH})$, spike length (SL), number of spikelets per spike (SS), number of kernels per spike (KS), 1000 kernel weight (TKW), and grain (GY) as described in Semahegn et al. (2020). Separate and combined analyses of variance were conducted using the GLM procedure in SAS version 9.3 (SAS Institute, 2012). Variance components for each trait were estimated using expected mean squares from the respective ANOVA results. Site and water regime were considered to be fixed factors, while genotype was considered as having random effect. Negative variance estimates were considered as zero (Robinson et al., 1955; Annicchiarico, 1997). Expected mean squares were calculated following Shimelis and Shiringani (2010), as presented in Table 6. The broad sense heritability values were calculated following Allard (1996). Genetic advance (GA) was calculated according to Johnson et al. (1955). Pearson correlation coefficients were estimated using the Statistical Software for Social Science version 24 (SPSS, 2016). Path coefficient analysis was conducted following Dewey and Lu (1959).

\section{Conclusion}

The tested lines exhibited significant genetic variation for all traits measured, providing essential genetic resources for bread wheat improvement and providing opportunities to identify genotypes and traits that have stability across water regimes. Traits such as DH, SL and SS exhibited high genetic variance, heritability and genetic advance, and these traits could be improved through direct selection under drought stress condition. TKW had favourable positive and strongest correlation with GY, which provides a basis for selection and improvement of GY under drought stress condition. Further genotyping with selected molecular markers will complement the present data set to select complementary genotypes for drought tolerance breeding.

\section{Acknowledgments}

Thanks are extended to Debre Zeit, Kulumsa and Mekassa Agricultural Research Centres for providing technical support. The Ethiopian Institute of Agricultural Research through Holetta Agriculture Research Centre is thanked for providing leave of absence and research support. This study was supported by The Alliance for a Green Revolution in Africa (AGRA) through the African Centre for Crop Improvement (ACCI).

\section{References}

Abate GT, Bernard T, Brauw AD, Minot N (2018) The impact of the use of new technologies on farmers' wheat yield in Ethiopia: evidence from a randomized control trial. Agric Econ. 49: 409-421.

Abraha MT, Hussein S, Laing M, Assefa K (2017) Genetic variation and trait association of tef [Eragrostis tef (Zucc.) Trotter] evaluated under optimal and moisture stressed environments. Aust J Crop Sci. 11: 241-247.

Ali MA, Nobe N, Nawab, Abbas A, Zulkiffal M, Sajjad M (2009a) Evaluation of selection criteria in Cicer arietinum L. using correlation coefficients and path analysis. Aust J Crop Sci. 3: 65-70.

Ali MA, Abbas A, Niaz S, Zulkiffal M, Ali S (2009b) Morphophysiological criteria for drought tolerance in sorghum (Sorghum bicolor) at seedling and post-anthesis stages. Int J Agric Biol. 11: 674-680.

Ali MA, Hussain M, Khan MI, Ali Z, Zulkiffal M, Anwar J, Sabir W, Zeeshan M (2010) Source-sink relationship between photosynthetic organs and grain yield attributes during grain filling stage in spring wheat (Triticum aestivum). Int J Agric Biol. 12: 509-515.

Ali MA, Jabran K, Awan SI, Abbas A, Ehsanullah, Zulkiffal M, Acet T, Farooq J, Rehman A (2011) Morpho-physiological diversity and its implications for improving drought tolerance in grain sorghum at different growth stages. Aust J Crop Sci. 5: 311-320.

Allard L (1996) Principles of Plant Breeding. John Wiley and Sons, Inc., London.

Annicchiarico P (1997) Joint regression vs AMMI analysis of genotype $\times$ environment interactions for cereals in Italy. Euphytica. 94: 53-62.

Anwar J, Ali MA, Hussain M, Sabir W, Khan MA, Zulkiffal M, Abdullah M (2009) Assessment of yield criteria in bread wheat through correlation and path analysis. J Anim Plant Sci. 19: 185-188.

Asfaw A, Blair MW (2014) Quantification of drought tolerance in Ethiopian common bean varieties. Agric Sci. 5: 124-139.

Badu-Apraku B, Yallou CG, Obeng-Antwi K, Alidu H, Talabi AO, Annor B, Oyekunle M, Akaogu I C, Aderounmu M (2017) Yield gains in extra-early maize cultivars of three breeding eras under multiple environments. Agron J. 109: 1-14.

Baranwal DK, Mishra VK, Vishwakarma MK, Yadav PS, Arun B (2012) Studies on genetic variability, correlation and path analysis for yield and yield contributing traits in wheat (Triticum aestivum). Plant Arch. 12: 99-104.

Bizeti HS, Carvalho CGPD, Souza JRPD, Destro D (2004) Path analysis under multicollinearity in Soybean. Braz Arch Biol Technol. 47: 669-676.

Dewey DR, Lu KN (1959) A correlation and path coefficient analysis of components of crested wheat grass seed production. Agron J. 51: 515-518. 
Dodig D, Zorić M, Kandic V, Perovic D, Surlan-Momirovic G (2012) Comparison of responses to drought stress of 100 wheat accessions and landraces to identify opportunities for improving wheat drought resistance. Plant Breed. 131: 369-379.

Farshadfar E, Rahmani S, Jowkar MM, Shabani A (2014) Estimation of genetic parameters and chromosomal localization of QTLs controlling agro-physiological indicators of drought tolerance in agropyron using wheatagropyron disomic addition lines. Aust J Crop Sci. 8: 133139.

FAO (2019) FAOSTAT. FAO, Rome. www.fao.org (accessed 21 June 2019).

Garcia del Moral LG, Rharrabti Y, Villegas D, Royo C (2003) Evaluation of grain yield and its components in durum wheat under Mediterranean conditions: An ontogenic approach. Agron J. 95: 266-274.

Gashaw A, Mohammed H, Singh H (2007) Selection criterion for improved grain yields in Ethiopian durum wheat genotypes. Afr Crop Sci J. 15: 25 - 31 .

Johnson HW, Robinson HF, Comstock RE (1955) Estimates of genetic and environmental variability in soybeans. Agron J. 47: 314-318.

Kandić V, Dodig D, Jović M, Nikolić B, Prodanović S (2009) The importance of physiological traits in wheat breeding under irrigation and drought stress. Genetika. 41: 11-20.

Kang MS (2002). Genotype-Environment Interaction: progress and prospects. In: Kang MS (ed) Quantitative Genetics, Genomics and Plant Breeding. CAB International, Wallingford, UK.

Khaliq I, Parveen N, Chowdhry MA (2004) Correlation and path coefficient analyses in bread wheat. Int J Agric Biol. 6: 633-635.

Khan MH, Dar AN (2010) Correlation and path coefficient analysis of some quantitative traits in wheat. Afr Crop Sci J. 18: 9-14.

Lobell DB, Gourdji SM (2012) The influence of climate change on global crop productivity. Plant Physiol. 160: 1686-1697.

Lopes MS, El-Basyoni I, Baenziger PS, Singh S, Royo C, Ozbek K, Aktas H, Ozer E, Ozdemir F, Manickavelu A, Ban T, Vikram $P$ (2015) Exploiting genetic diversity from landraces in wheat breeding for adaptation to climate change. J Exp Bot. 66: 3477-3486.

Mafouasson HNA, Gracen V, Yeboah MA, NtsombohNtsefong G, Tandzi LN, Mutengwa CS (2018) Genotype-byEnvironment interaction and yield stability of maize single cross hybrids developed from tropical inbred lines. Agron. 8 (5):62.

Mathew I, Shimelis H, Mwadzingeni L, Zengeni R, Mutema M, Chaplot V (2018) Variance components and heritability of traits related to root: shoot biomass allocation and drought tolerance in wheat. Euphytica. 214: 225.

Marti J, Slafer GA (2014) Bread and durum wheat yields under a wide range of environmental conditions. Field Crops Res. 156: 258-271.

Mwadzingeni L, Shimelis H, Tsilo T, Tesfay S (2016) Screening of bread wheat genotypes for drought tolerance using phenotypic and proline analyses. Front Plant Sci. 7: 1-12.

Mwadzingeni L, Shimelis H, Tsilo TJ (2017) Variance components and heritability of yield and yield components of wheat under drought-stressed and non-stressed conditions. Aust J Crop Sci. 11: 1425-1430.
Negassa A, Shiferaw B, Koo J, Sonder K, Smale M, Braun HJ, Gbegbelegbe S, Guo Z, Hodson D, Wood S, Payne T, Abeyo B (2013) The potential for wheat production in Africa: Analysis of biophysical suitability and economic profitability. CIMMYT, Mexico, D.F.

Okechukwu EC, Agbo CU, Uguru MI, Ogbonnaya FC (2015) Germplasm evaluation of heat tolerance in bread wheat in Tel Hadya, Syria. Chil J Agric Res. 76(1):9-17.

Pfeifer M, Kugler KG, Sandve SR, Zhan B, Rudi H, Hvidsten TR, Mayer KFX, Olsen OA (2014) Genome interplay in the grain transcriptome of hexaploid bread wheat. Science. 345(6194):1250091.

Rashid S, Lemma S (2014) Public Wheat Imports since 2008: The Rationales and Cost Effectiveness. Research for Ethiopia's Agriculture Policy (REAP). International Food Policy Research Institute, Washington, DC.

Riaz-ud-din GM, Subhani N, Ahmad M, Hussain, Rehman AU (2010) Effect of temperature on development and grain formation in spring wheat. Pak J Bot. 42: 899-906.

Robinson HF, Comstock RE, Harvey PH (1955) Genetic variances in open pollinated varieties of corn. Genetics. 40: 45-60.

SAS Institute (2011) SAS/IML 9.3 User's Guide Cary, NC: SAS Institute Inc.

Seher M, Shabbir G, Rasheed A, Gul Kazi A, Mahmood T, Mujeeb-Kazi A (2015) Performance of diverse wheat genetic stocks under moisture stress condition. Pak J Bot. 47: 21-26.

Semahegn Y, Shimelis H, Laing M, Mathew I (2020) Evaluation of bread wheat (Triticum aestivum L.) genotypes for yield and related traits under drought stress conditions. Acta Agr Scand B-S-P. 70(6):474-484.

Shavrukov Y, Kurishbayev A, Jatayev S, Shvidchenko V, Zotova L, Koekemoer F, de Groot S, Soole K, Langridge P (2017) Early Flowering as a Drought Escape Mechanism in Plants: How Can It Aid Wheat Production? Front Plant Sci. 8:1950.

Shimelis H, Shiringani R (2010) Variance components and heritabilities of yield and agronomic traits among cowpea genotypes. Euphytica. 176: 383-389.

SPSS (Statistical Product and Service Solutions) (2016) SPSS for Windows Release 24.0. SPSS Inc. 1989-2016. IBM Company.

Sreckov Z, Nastasic A, Bocanski J, Djalovic I, Vukosavljev M, Jockovic B (2011) Correlation and path analysis of grain yield and morphological traits in test-cross populations of maize. Pak J Bot. 43: 1729-1731.

Subhani GM, Chowdhry MA (2000) Correlation and path coefficient analysis in bread wheat under drought stress and normal conditions. Pak J Biol Sci. 3: 72-77.

Tadesse W, Manes Y, Singh RP, Payne T, Braun HJ (2010) Adaptation and performance of CIMMYT spring wheat genotypes targeted to high rainfall areas of the world. Crop Sci. 50: 240-248.

Tadesse W, Bishaw Z, Assefa S (2019) Wheat production and breeding in Sub-Saharan Africa: Challenges and opportunities in the face of climate change. Int J Clim Chang Str. 11: 696-715. 